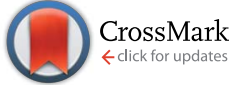

Cite this: RSC Adv., 2016, 6, 50933
Received 16th March 2016 Accepted 18th May 2016

DOI: $10.1039 / \mathrm{c} 6 \mathrm{ra07002g}$

www.rsc.org/advances

\section{Synthesis of copper-silver bimetallic nanopowders for a biomedical approach; study of their antibacterial properties}

\author{
Céline Rousse, ${ }^{a}$ Jérôme Josse, ${ }^{b}$ Valérie Mancier, ${ }^{a}$ Samuel Levi, ${ }^{a}$ Sophie C. Gangloff ${ }^{\star b}$ \\ and Patrick Fricoteaux ${ }^{\star a}$
}

Copper-silver nanopowders (NPs) are synthesized using a combination of sonoelectrodeposition for the inner core and galvanic replacement reaction for the outer shell. These combined techniques provide pure copper core NPs and allow the replacement of the surface copper atoms by silver atoms. The different $\mathrm{Cu}-\mathrm{Ag}$ NPs are characterized by transmission electron microscopy, centrifugal liquid sedimentation, X-ray diffraction, X-ray photoelectron spectroscopy and energy dispersive X-ray spectroscopy. The diameter of NPs is approximately equal to $7 \mathrm{~nm}$. X-ray photoelectron spectroscopy results tend to support a core-shell structure. The bactericidal properties of these NPs are tested against both Staphylococcus aureus (Gram-positive) and Escherichia coli (Gram-negative) bacteria. The efficiency of these NPs seems essentially due to the release of $\mathrm{Cu}^{2+}$ and $\mathrm{Ag}^{+}$ions. The study of different compositions of $\mathrm{Cu}-\mathrm{Ag}$ NPs exhibits a good compromise against both $\mathrm{S}$. aureus and $E$. coli when the silver atomic percentage is superior to $40 \%$. Finally, tests of wound dressings impregnated with $\mathrm{Cu}_{50} \mathrm{Ag}_{50}$ NP are performed and exhibit successfully their bactericidal properties.

\section{Introduction}

Due to their unique nanostructuration, nanostructures increase the active surface and may therefore enhance the initial electrical, optical and chemical properties of a material. They can be employed for example in magnetic recording, ${ }^{\mathbf{1 , 2}}$ catalysis $^{\mathbf{3 , 4}}$ or medicine (diagnosis or treatment)..$^{5-7}$

Metallic elements such as $\mathrm{Ag}$ or $\mathrm{Cu}$, known for their antibacterial properties, were often cited as being very active against both Gram-positive and Gram-negative bacteria. ${ }^{8-10}$ At the nanometric scale, the properties of metal or oxide are generally amplified as reviewed by Hajipour et al. ${ }^{11}$ Nevertheless, since the experiments were performed on different bacteria and/or different nanoparticles (composition, size, etc.), the individual results are difficult to generalize. The silver nanoparticles were certainly the most studied and were tested on different bacteria $^{\mathbf{1 2 , 1 3}}$ mostly against Escherichia coli (E. coli, Gramnegative) and Staphylococcus aureus (S. aureus, Gram-positive). ${ }^{14-17}$ For example, Kim et al. ${ }^{15}$ have reported a better efficiency of silver against $E$. coli than $S$. aureus. The comparison between the antibacterial activity of $\mathrm{Ag}$ and $\mathrm{Cu}$ or $\mathrm{Ag}-\mathrm{Cu}$ (bimetal, alloy or mixture) was also studied and did not always give the same conclusions. Some authors ${ }^{\mathbf{1 8 , 1 9}}$ have found that

${ }^{a}$ LISM, EA 4695, UFR Sciences Exactes et Naturelles, Université de Reims Champagne-Ardenne, Reims, France.E-mail: patrick.fricoteaux@univ-reims.fr

${ }^{b}$ BIOS, EA 4691, UFR Pharmacie, Université de Reims Champagne-Ardenne, Reims, France. E-mail: sophie.gangloff@univ-reims.fr silver presents the best properties against both $E$. coli and $S$. aureus. For Mat Zain et al., ${ }^{\mathbf{2 0}}$ the antibacterial effect increased according to the following sequence: $\mathrm{Cu}<\mathrm{Cu}$ and $\mathrm{Ag}$ mixture $<$ $\mathrm{Ag}<\mathrm{Cu}-\mathrm{Ag}$ alloys. On the contrary, Valodkar et al. ${ }^{21}$ have found a more important bacterial growth inhibition in the presence of copper as compared to silver; Tamayo et al..$^{22}$ reported the same conclusion concerning Listeria monocytogenes. They attributed this phenomenon to a better release of copper ions compared to silver ions. Ruparelia et al. ${ }^{19}$ have found the opposite, i.e. better action of silver compared to copper, and explained their results by the presence of a copper oxide layer that decreases the copper ions release. Ren et $a .^{23}$ have compared the action of $\mathrm{Cu}$ and $\mathrm{CuO}$ and have found $\mathrm{Cu}$ to have the best antibacterial activity. The latter result seems to corroborate those of Ruparelia et al. ${ }^{\mathbf{1 9}}$ For numerous authors, the bactericidal effects of $\mathrm{Cu}$ and $\mathrm{Ag}$ nanoparticles are due to the release of metal ions ${ }^{19,21-23}$ and to their penetration through the bacterial cell wall. ${ }^{22}$ The release of metal directly within the bacteria accelerating its destruction is bacteria type dependent and could be due to the difference between the bacteria cell walls. For Mat Zain et al. ${ }^{20}$ Grampositive bacteria are more susceptible to nanoparticles than Gram-negative bacteria owing to their more complex cell-wall structure. Other studies reported an adsorption impact of nanoparticles on bacteria surface. The nanoparticles with positive zeta potential have an electrostatic attraction on bacteria with negative charge surface that enhances the total effect of metals. ${ }^{\mathbf{1 2 4 2 , 2 5}}$ Another important parameter that can explain the difference in bacterial susceptibility is the size of the 
nanoparticles used in the studies. It was often reported that antibacterial activity increases as the size of particles decreases..$^{13,20,26,27}$

Overall, silver seems to have the broader antibacterial spectrum and this explains the interest to functionalize different material with $\mathrm{Ag}$ nanoparticles in order to enhance their bactericidal properties. For example, for food packaging applications, Esteban-Tejeda et $a .^{28}$ prepared a soda-lime glass containing silver nanoparticles and Azlin-Hasim et al. ${ }^{29}$ have tested silver nanodots in polystyrene- $b$-polyethylene. For the textile industry, to create healing clothing, Ag nanoparticles insertions tests in various cloths were performed. ${ }^{27,30-33}$ At the medical level, the impregnation of silver nanoparticles into cellulose for antimicrobial wound dressings were tested against $E$. coli et $S$. aureus by Maneerung et al. ${ }^{30}$

One of the issues concerning these nanoparticles is their cost, especially when large amounts are needed, for example in the domain of water purification. To solve this problem and reduce the cost, two strategies have emerged: the use of a mixture of $\mathrm{Ag}$ and $\mathrm{Cu}$ particles ${ }^{18,34}$ or the creation of core-shell particles. Recently, Chen et al. ${ }^{35}$ have studied the anti-oxidation and antibacterial properties of $\mathrm{Cu}-\mathrm{Ag}$ core-shell microparticles using commercial micrometric $\mathrm{Cu}$ particles that they have coated with silver by chemical reduction. They demonstrated that the antibacterial activity is linked to the silver percentage in the particles.

In the present study, $\mathrm{Cu}-\mathrm{Ag}$ bimetallic nanostructured particles were produced by sonoelectrodeposition, followed by galvanic replacement reaction. The first method was chosen to synthesize the copper core as it presented numerous advantages: simplicity, versatility, low cost and adaptable to an industrial scale ${ }^{36}$ high yield of production, ${ }^{37}$ absence of byproducts and possibility to work in aqueous media ${ }^{38}$ without any supplementary chemical products. Moreover, numerous studies showed that the NPs obtained by sonoelectrodeposition have very small diameters (less than $10 \mathrm{~nm}) \cdot{ }^{39-42}$ The $\mathrm{Cu}-\mathrm{Ag}$ bimetallic NPs were analyzed for their antibacterial activities and for their ability to be active after wound dressings impregnation. For the first time, the effects against $S$. aureus and $E$. coli of such bimetallic nanostructures (obtained by sonoelectrodeposition) were reported, supporting their suitability for use as bactericidal materials.

\section{Experimental section}

\subsection{Copper core elaboration}

The copper NPs were synthesized using an out-of-phase pulsed sonoelectrochemical setup $^{\mathbf{4 2}}$ with a classical three-electrode electrochemical cell. The working electrode consists of a titanium cylinder (called sonotrode or horn) connected to a potentiostat and to an ultrasonic generator. The counter electrode was a pure copper rod (99.9\%) and the reference electrode was a saturated mercury sulphate electrode (SSE). The aqueous solution for copper electrolysis was made with copper sulphate pentahydrate $\left(\mathrm{CuSO}_{4} \cdot 5 \mathrm{H}_{2} \mathrm{O}\right.$ from Panreac) at $0.1 \mathrm{~mol} \mathrm{~L}^{-1}$ and sulfuric acid $\left(\mathrm{H}_{2} \mathrm{SO}_{4}\right.$ from Chimie-Plus) at $0.9 \mathrm{~mol} \mathrm{~L}^{-1}$. The temperature of the copper electrolyte was regulated at $30^{\circ} \mathrm{C}$.
The potentiostat and the ultrasonic system were independent and work alternately. A rest period was also applied between ultrasounds generation and electrolysis in order to reduce acoustic streaming in solution, diffusion layer and possible electronic interactions. In order to produce the copper NPs, a pulse of polarization $(-1 \mathrm{~V} v$ s. SSE; pulse duration $=100$ $\mathrm{ms}$ ) was applied to produce nuclei at the surface of the sonotrode. Those nuclei were immediately pulled off the surface using a $100 \mathrm{~W} \mathrm{~cm}^{-2}$ power ultrasonic pulse for $100 \mathrm{~ms}$. Applied potential for electrolysis and ultrasound pulses were used out of phase, without any latency between them. Then a free time of $100 \mathrm{~ms}$ was applied to let the diffusion of electrochemical species. The sequence of these pulses was repeated to produce a large amount of $\mathrm{Cu} \mathrm{NP}$.

After the sonoelectrochemical synthesis, the copper nanoparticle suspension was filtered under vacuum using a hydrophilic polyethersulfone membrane. Several washings in large volumes of deionized water and with deoxygenated ethanol were performed. The NP was removed from the filter by immersion in degassed ethanol and sonication in an ultrasonic tank. Finally, the obtained copper NP was dried after sedimentation and placed under vacuum to avoid oxidation.

\subsection{Silver coating elaboration}

For the silver coating elaboration, the copper nanoparticles were dipped into a stirred solution of silver(I) ions in order to cover them with a shell of metallic silver. As described by Fricoteaux et al.,$^{\mathbf{4}}$ the silver solution was prepared with silver oxide $\left(\mathrm{Ag}_{2} \mathrm{O}\right.$ from Fluka with $\left.[\mathrm{Ag}(\mathrm{I})]=10^{-3} \mathrm{~mol} \mathrm{~L}^{-1}\right)$, sulphamic acid $\left(\mathrm{H}_{3} \mathrm{NO}_{3} \mathrm{~S}\right.$ from Chimie-Plus; $\left.0.2 \mathrm{~mol} \mathrm{~L}^{-1}\right)$, ethylenediaminetetraacetic acid (EDTA from Chimie-Plus; $0.1 \mathrm{~mol}$ $\left.\mathrm{L}^{-1}\right)$ and sodium hydroxide pellets $(\mathrm{NaOH}$ from Chimie-Plus; until $\mathrm{pH}=9.3$ ). Silver oxide and sulphamic acid were first dissolved in deionized water. EDTA and $\mathrm{NaOH}$ were slowly added together to the previous solution. This order of insertion prevents the formation of unsolvable silver complexes.

The galvanic replacement reaction of silver (eqn (1)) was performed at ambient temperature.

$$
2 \mathrm{Ag}(\mathrm{I})+\mathrm{Cu} \rightarrow \mathrm{Cu}(\mathrm{II})+2 \mathrm{Ag}
$$

The obtained silver atomic percentage increases with the duration of copper immersion inside the silver solution.

\subsection{Nanopowder characterization}

X-ray diffraction (XRD) analyses were carried out using a Brucker D8 Advance X-ray diffractometer equipped with a copper anticathode $\left(\lambda_{\mathrm{CuK} \alpha}=1.54056 \AA\right.$ ). XRD diffractograms were recorded in Bragg Brentano configuration. Particle size distribution was obtained by centrifugal liquid sedimentation (CLS) of a powder suspension in ethanol with a CPS Disc Centrifuge DC20000 particle size analyser (CPS Instruments) with a rotation speed equal to $20000 \mathrm{rpm}$.

The zeta potential was measured by a Delsa ${ }^{\mathrm{TM}}$ Nano $\mathrm{C}$ particle analyser (BeckMan Coulter) computer driven with the software Delsa ${ }^{\mathrm{TM}}$ Nano 3.73 (BeckMan Coulter Inc.). The 
measurements were done in distilled water at constant temperature $\left(25^{\circ} \mathrm{C}\right)$ by means of a Peltier device. The chemical composition was investigated by energy dispersive X-ray spectroscopy (EDXS) using a JEOL 1300 microprobe coupled with a JEOL JSM 6440LA scanning electron microscope (SEM). All the EDXS atomic percentages are given with an accuracy of $4 \%$. Surface composition was analyzed with an X-ray photoelectron spectroscopy (XPS) system. The apparatus used was a SSX-100 system using $\mathrm{Al} \mathrm{K} \alpha \mathrm{X}$-rays, with spectra recorded at $35^{\circ}$ takeoff angle. Transmission electron microscopy (TEM) was performed using a Philips CM20 ultra twin SEM.

\subsection{Wound dressing functionalization}

The commercial wound dressing used in this study (Leukomed ${ }^{\circledR}$, BSN Medical) is sterile, permeable to air and water. It is composed of a white polyurethane non-weaved support (Hypafix $\circledast$ ) and a neutral compress, and it does not have any intrinsic antibacterial activity. To insert nanoparticles into the wound dressing, a sample $\left(1 \mathrm{~cm}^{2}\right)$ was immersed into deionized water containing $0.5 \mathrm{~g} \mathrm{~L}^{-1}$ or $1.0 \mathrm{~g} \mathrm{~L}^{-1}$ of $\mathrm{Cu}-\mathrm{Ag} \mathrm{NP}$. Ultrasonic horn was employed at high power $\left(204 \mathrm{~W} \mathrm{~cm}^{-2}\right)$ to shake the solution during $20 \mathrm{~min}$. The wound dressing piece was then removed from the aqueous solution and dried under sterile controlled atmosphere at $18{ }^{\circ} \mathrm{C}$ during $12 \mathrm{~h}$. The quantity of impregnated powder inside the wound dressing was deduced by comparison between the quantity of silver introduced and the quantity remaining in the solution after impregnation. The first one was obtained by weighing the introduced silver NP; the second one by inductively coupled plasma atomic emission spectrometry analysis (ICP-AES, Varian-spectrometer) of the solution after residual silver dissolution with nitric acid. The deduced final impregnated wound dressing concentrations were $3 \mathrm{mg} \mathrm{cm}^{-2}$ (for an initial concentration at $0.5 \mathrm{~g} \mathrm{~L}^{-1} \mathrm{of} \mathrm{Cu}-$ $\mathrm{Ag} \mathrm{NP}$ ) and $6 \mathrm{mg} \mathrm{cm}^{-2}$ (for an initial concentration at $1.0 \mathrm{~g} \mathrm{~L}^{-1}$ of $\mathrm{Cu}-\mathrm{Ag} \mathrm{NP})$.

\subsection{Antibacterial assays}

The antibacterial assays were evaluated on $S$. aureus 8325-4 (prophage-free NCTC 8325) and E. coli DH5- $\alpha$ (Invitrogen). The bacteria, taken from a frozen aliquot, were first stripped on a Trypto-Casein-Soy (TCS, Biomérieux) agar plate to isolate colonies. Two colonies were inoculated into TCS broth and cultured during 12 hours at $37^{\circ} \mathrm{C}$. The bacteria were then inoculated into fresh TCS broth to obtain a suspension with an optical density equal to $0.1\left(A_{620} \mathrm{~nm}\right)$. The bacteria were then cultured at $37{ }^{\circ} \mathrm{C}$ up to a culture absorbance $\left(A_{620} \mathrm{~nm}\right)$ between 0.2 and 0.4 , so that the bacteria were in a growing phase. Thereafter, $2 \mathrm{~mL}$ of the culture was spread on the surface of fresh agar plates. The excess was removed and the plates were prepared for the assay.

To detect the NPs antibacterial efficiency, the principle of the antibiograms was used. In the present study, the impregnated disks were replaced by wells. The $6 \mathrm{~mm}$ diameter wells were punched at equal distance in the agar plate and calibrated aqueous solutions of NPs $(2 \mathrm{mg}$ in $30 \mu \mathrm{L})$ was deposited in the well. The bactericidal effects of aqueous solution of NPs were compared with dry NPs, copper salts in solution and massive copper (Goodfellow 99.9\%). To follow the calibrated wound dressing antibacterial activity, the samples $\left(1 \mathrm{~cm}^{2}\right)$ were laid directly on the surface of the agar plates. Each time, a positive (bleach disposed in a well) and a negative (bare wound dressing laid on agar) control were included in the test. The plates were then incubated at $37^{\circ} \mathrm{C}$ and the radius of the growth inhibition zones from the center of the deposit were measured after 24 hours of incubation. Each assay was repeated at least 3 times.

\section{Results}

\subsection{Materials characterization}

$\mathrm{Cu}$ and $\mathrm{Cu}-\mathrm{Ag}$ NPs with different compositions were characterized by different methods. Except for zeta potential measurements, the $\mathrm{Cu}_{50}-\mathrm{Ag}_{50} \mathrm{NP}$ was chosen as an example to exhibit the different results when numerous compositions of $\mathrm{Cu}-\mathrm{Ag}$ nanoparticles were analyzed. TEM analyses revealed that $\mathrm{Cu}$ and $\mathrm{Cu}-\mathrm{Ag}$ NPs are roughly spherical with heterogeneous diameters (Fig. 1a1 and b1). Using the centrifugal liquid sedimentation method, the particle size distribution was determined and the hydrodynamic diameter is nearly the same before and after galvanic replacement reaction. It varies between 5 and $10 \mathrm{~nm}$ with predominance for a diameter equal to $7 \mathrm{~nm}$ (Fig. 1a2 and b2).

The XRD diffractogram of the copper NPs (Fig. 2a) exhibits diffraction peaks corresponding mainly to the metallic copper (JCPDS file 004-0836) with only very low traces of copper oxide (I) $\left(\mathrm{Cu}_{2} \mathrm{O}\right)$ (JCPDS file 005-0667). After galvanic replacement reaction (Fig. 2b), only metallic silver diffraction peaks (JCPDS file 004-0783) and copper diffraction peaks (JCPDS file 004-0836) are present, indicating that the NPs are not a $\mathrm{Cu}-\mathrm{Ag}$ alloy but two distinct metals.

To study the repartition of silver on copper core, the $\mathrm{Cu}_{50^{-}}$ $\mathrm{Ag}_{50} \mathrm{NP}$ was characterized by XPS and EDXS. The comparative results are exhibited in Table 1 . It shows that the silver percentage values obtained by XPS is larger than the ones obtained by EDXS. Given that XPS is a surface analysis technique, this highlights that the silver percentage is higher on the surface than in the center of the particle. This proves that the particles obtained are richer in silver at the surface suggesting a core-shell structure. Such $\mathrm{Cu}-\mathrm{Ag}$ core-shell structures were already obtained for submicro and microparticles..$^{35,42,44,45,47}$ As shown in a previous work ${ }^{42}$ the silver shell widely modifies the conversion reaction kinetic that becomes very slow from about 40 at $\%$ of silver. This was explained by the presence of the silver coat limiting the access to the subjacent copper. This point rules out the formation of Janus structures in which copper would be easily accessible until the total conversion. In this case, no slow-down of kinetic would then be observed.

Finally, the zeta potential of the NPs was measured. Fig. 3 exhibits its evolution versus the atomic silver percentage. The obtained zeta potential is mainly negative for NPs with a composition of 0 to 75 atomic silver percentages. It becomes positive when the silver atomic percentage is over $75 \%$. 

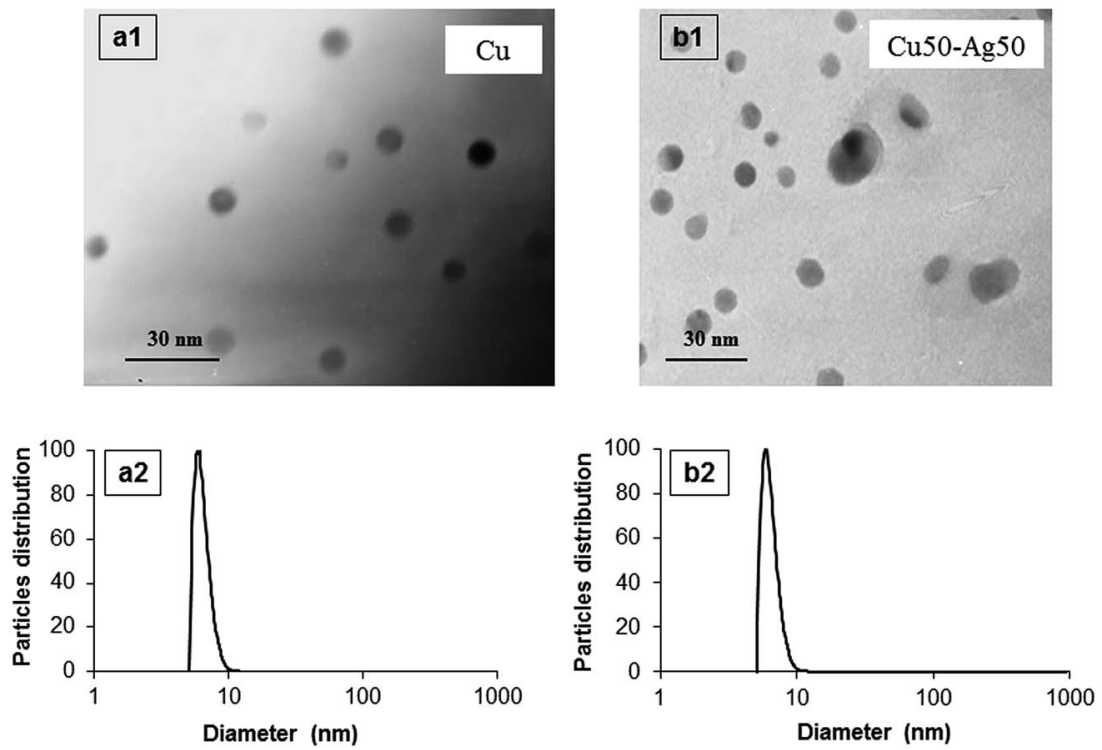

Fig. 1 Characterization of $\mathrm{Cu}$ (a1 and a2) and $\mathrm{Cu}_{50}-\mathrm{Ag}_{50}$ (b1 and b2) NPs: (1) transmission electron microphotograph, (2) particle size distribution by CLS method.
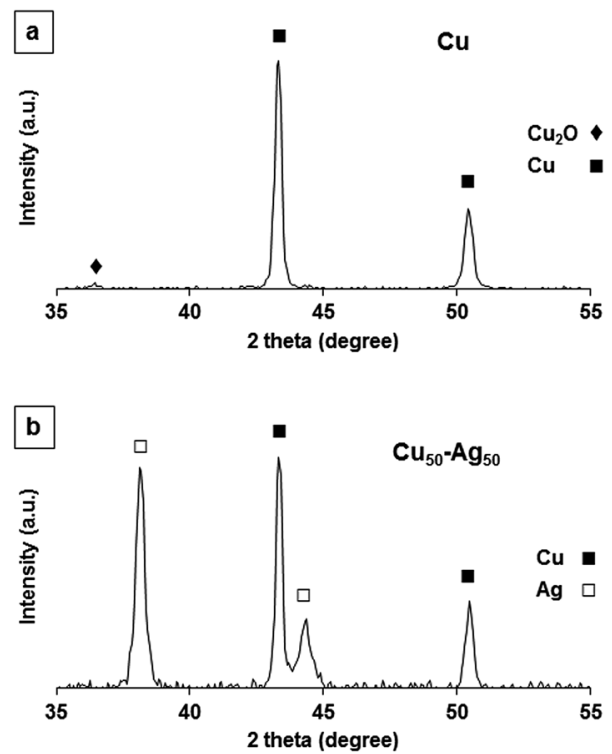

Fig. 2 X-ray-diffractograms recorded in Bragg-Brentano conditions for $\mathrm{Cu}(\mathrm{a})$ and $\mathrm{Cu}_{50}-\mathrm{Ag}_{50}$ (b) NPs.

Table 1 Comparison of at\% of $\mathrm{Ag}$ in nanoparticles between EDXS $( \pm 4 \%)$ and XPS $( \pm 2 \%)$ method

\begin{tabular}{ll}
\hline EDXS results (at\% Ag) & XPS results (at\% Ag) \\
\hline 20 & 58 \\
50 & 88
\end{tabular}

\subsection{Antibacterial activities of the core shell particles}

Antibacterial assays on agar plates were performed on $S$. aureus and $E$. coli to evaluate their sensitivity against the different NPs.

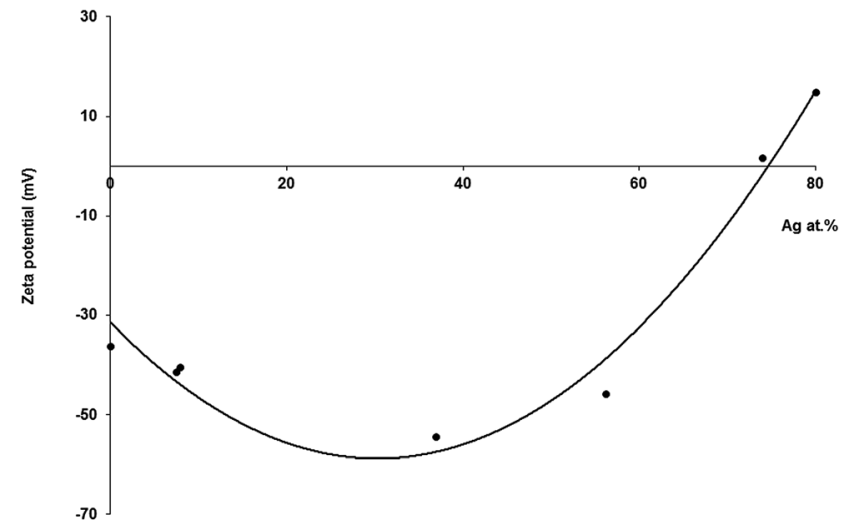

Fig. 3 Zeta potential of $\mathrm{Cu}$ and $\mathrm{Cu}-\mathrm{Ag}$ NPs versus silver atomic percentage of NPs.

All bactericide assays were conducted in nanoparticles dispersed in aqueous solution because with dry nanoparticles the inhibition zones were not homogenous around the wells due to the powders landing in the well resulting in a various diffusion concentration in the agar. Different concentrations of nanopowders were tested before choosing an ideal quantity of introduced nanoparticles. A very weak antibacterial activity is discernable for $0.1 \mathrm{mg}$ of NPs (Fig. 4a). For higher quantities, the inhibition zone is marked and a quantity equal to $2 \mathrm{mg}$ was chosen for the following tests. As seen in Fig. 4b, S. aureus bacteria present susceptibility to copper and to $\mathrm{Cu}_{50}-\mathrm{Ag}_{50} \mathrm{NPs}$ (the choice of this particular composition will be justified at the end of this paragraph 3.2.). The inhibition zone is slightly larger with copper NPs compared to $\mathrm{Cu}_{50}-\mathrm{Ag}_{50}$ NPs. This can be explained by the fact that copper is directly accessible in sample 2. However, as seen in sample 3, the silver coating does not hamper the antibacterial activity of copper against $S$. aureus. This is explained by the porosity of the silver shell. 

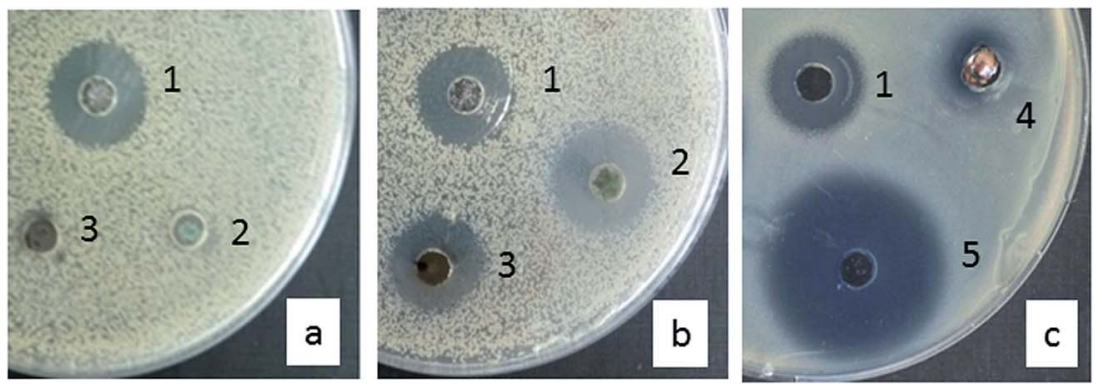

Fig. 4 Diffusion antibacterial assay against $S$. aureus (a) with $0.1 \mathrm{mg}$ of NP (b) with $2 \mathrm{mg}$ of NP (c) comparison between massive and ionic copper. 1: bleach, 2: Cu NP, 3: $\mathrm{Cu}_{50}-\mathrm{Ag}_{50} \mathrm{NP}, 4$ : massive $\mathrm{Cu}\left(0.1 \mathrm{~g}\right.$ and $30 \mu \mathrm{L}$ of Trypto-Casein-Soy (TCS)), 5: $\mathrm{Cu}\left(\mathrm{NO}_{3}\right)_{2}\left(30 \mu \mathrm{L} \mathrm{of} 1 \mathrm{~mol} \mathrm{~L}{ }^{-1}\right)$.

In order to verify that the release of ions inside the agar has a preponderant impact on the bacteria in the diffusion assay, the effect of $\mathrm{Cu}^{2+}$ ions $\left(\mathrm{Cu}\left(\mathrm{NO}_{3}\right)_{2}\right.$ solution) and massive copper were also tested for their antibacterial effects (Fig. 4c). The growth inhibition zone observed with sample 5 corresponding to $\mathrm{Cu}^{2+}$ ions is much larger than the one corresponding to the massive copper (sample 4). This result indicates clearly a greater activity of ions as compared to metallic copper.

The different core-shell NPs produced were also tested against $E$. coli. The impact of the silver atomic percentage on $S$. aureus and $E$. coli growth inhibition is summarized in Fig. 5. $S$. aureus is sensitive for each tested NP. The response against $S$. aureus can be considered as constant whatever the silver atomic percentage. For each tested composition, S. aureus is more sensitive than $E$. coli. Note that no bactericide properties against $E$. coli were observed for an atomic silver percentage inferior to $40 \%$ (the powder was deposited in well of a $6 \mathrm{~mm}$ diameter). Beyond 40 at\% of silver, the activity becomes effective and increases with silver percentage. Consequently, to be efficient against both $S$. aureus and $E$. coli, the atomic silver percentage of theses NPs needs to be superior to $40 \%$. With a composition of $\mathrm{Cu}_{50}-\mathrm{Ag}_{50}$, the response again $E$. coli is correct even if it is not the best one (compared to one obtained with $\mathrm{Cu}_{20}-\mathrm{Ag}_{80}$ ). For the following assays, the composition of $\mathrm{Cu}_{50}-\mathrm{Ag}_{50}$ was selected to impregnate wound dressings for different reasons. Firstly, the time of $\mathrm{Cu}_{50}-\mathrm{Ag}_{50}$ preparation was about five times shorter than

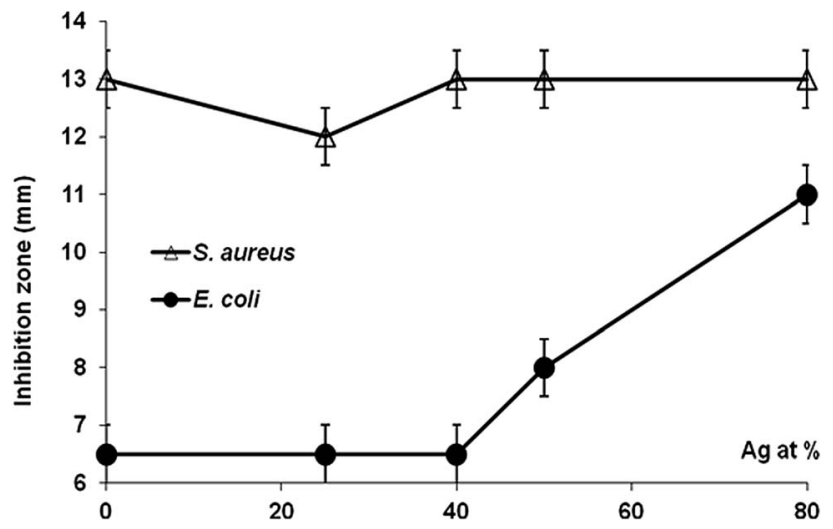

Fig. 5 Antibacterial activity against $S$. aureus and against $E$. coli versus silver atomic percentage of NPs.
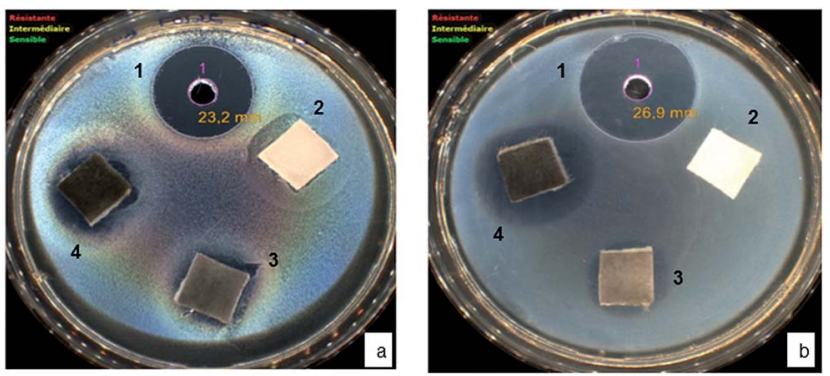

Fig. 6 Diffusion antibacterial assay with impregnated wound dressing by $\mathrm{Cu}_{50}-\mathrm{Ag}_{50}$ NPs. (a) S. aureus, (b) E. coli. 1: bleach, 2: bare wound dressing, 3: impregnated wound dressing of $\mathrm{Cu}_{50}-\mathrm{Ag}_{50}\left(3 \mathrm{mg} \mathrm{cm}^{-2}\right)$, 4: impregnated wound dressing of $\mathrm{Cu}_{50}-\mathrm{Ag}_{50}\left(6 \mathrm{mg} \mathrm{cm}^{-2}\right)$.

for $\mathrm{Cu}_{20}-\mathrm{Ag}_{80}{ }^{42}$ Secondly, its response again $E$. coli is satisfactory and allows using a minimum of silver.

\subsection{Wound dressing antibacterial activity}

Wound dressings impregnated after immersion inside NP solution under ultrasound (containing 3 or $6 \mathrm{mg} \mathrm{cm}^{-2}$ of NP) were laid on the agar covered with bacteria; the face intended to be in contact with the skin was in contact with the agar. With this setting, the impregnated samples show antibacterial activities on both $S$. aureus and E. coli (Fig. 6) in comparison to the plain wound dressing that serves as the negative control for antibacterial activity. A gradual effect of the $\mathrm{Cu}_{50}-\mathrm{Ag}_{50} \mathrm{NP}$ impregnated wound dressing can be seen between $3 \mathrm{mg} \mathrm{cm}^{-2}$ and $6 \mathrm{mg} \mathrm{cm} \mathrm{cm}^{-2}$ both against $S$. aureus (Fig. 6a) and E. coli (Fig. 6b). In parallel to the increased concentrations of the NP on the wound dressing, the measured inhibition zone increased from 19.5 to $21.0 \mathrm{~mm}$ for $S$. aureus (Fig. 6a) and for E. coli, from 18.7 to $27.4 \mathrm{~mm}$ (Fig. $6 \mathrm{~b}$ ).

\section{Discussion}

Silver or copper have been used as antimicrobial agents over the centuries. Currently, there is a renewed interest for inorganic nanoparticles like silver and copper as bactericide compounds due to their low cytotoxicity, known bacterial killing properties and their low ability to induce resistance mechanisms. ${ }^{46}$ 
The antibacterial effects of silver or copper nanoparticles have been widely observed but their mechanisms of action are not fully understood, due mainly to bacterial physiology and enzyme mechanisms diversity. Most of the studies have highlighted that a direct contact between the nanoparticles and the bacteria leads to damages in the bacteria cell wall and/or membrane. As a second step, this rupture of the cell-wall permeability allows the penetration of nanoparticles into the bacteria and an enhanced alteration of biological molecules by nanoparticles. These bactericidal effects of metallic nanoparticles are generally attributed to the induction of an oxidative stress through the release of reactive oxygen species (ROS). Hwang et $a{ }^{47}$ reported for example that $\mathrm{Ag}$ ions induce ROS that consequently alter bacterial compounds. It was also reported that metallic and ionic forms of copper produce hydroxyl radicals that damage both major proteins and DNA and that silver ions bind to sulfur, oxygen and nitrogen of essential biological molecules thus inhibiting bacterial growth. ${ }^{\mathbf{1 0 , 1 1 , 2 5}}$

Considering their respective antibacterial spectrum - copper is very active against $S$. aureus while silver is more efficient against $E$. coli - the combination of copper and silver in a single nanoparticle is therefore interesting. Many efforts have recently been made to synthesize specific copper/silver nanostructures, with long lasting effects, high chemical stability and low cytotoxicity. With such a core-shell arrangement the formation of an oxide copper oxidation is avoided thanks to the silver coating. ${ }^{35,48}$ In the present study, $\mathrm{Cu}-\mathrm{Ag}$ core-shell nanostructures were obtained using sonoelectrolysis followed by galvanic replacement reaction. These core-shell nanostructures allowed an increase of the reactive surface and a decrease of the total amount of each metal, specially the covering one, with effective low cost methods.

As seen in the antibacterial assays, looking at the efficiency of different copper physical states of matter against $S$. aureus, it appears that the $\mathrm{Cu}^{2+}$ ions are much more effective as compared to massive copper. The growth inhibition zone observed with copper NP is more important than with massive copper (Fig. 4). The fact that massive copper does not diffuse into the agar explains this relative bacterial insensitivity. However the presence of a slight inhibition zone shows that part of the bacteria is destroyed and this necessarily results from the release of $\mathrm{Cu}^{2+}$ ions in the growth medium and proves the preponderant role of released ions against these bacteria.

Even if the ions release is enhanced by nanometric scale, the composition (atomic percentage of copper and silver) is nevertheless important to define for bactericide applications as seen from Fig. 5. Although all the core-shell NPs present a good activity against $S$. aureus, due principally to the presence of copper, these core-shell NPs start to present an interesting activity against $E$. coli only when the percentage of atomic silver is over 40 at\%, confirming the different action mechanisms of both metals. It can be noticed that even if the copper is silver coated, the covering is not totally compact since the galvanic replacement reaction (eqn (1)) continues until reaching values close to $80 \mathrm{Ag}$ at\%. This phenomenon is classic in the case of galvanic replacement reaction and stands from the presence of porosity in the replacement layer ${ }^{49}$ allowing the release of ions from the core.
The difference in the cell walls of Gram-positive and Gramnegative bacteria could explain the difference of mechanisms between copper and silver. Gram-positive bacteria like $S$. aureus present a cell wall that allows the diffusion of small molecule, unlike the more complex cell wall of Gram-negative bacteria like E. coli, bounded with an outer lipid membrane. Indeed, Gramnegative cell wall also notably differs from the Gram-positive one by the presence in its outer membrane of lipopolysaccharides that enhances the negative charge of the cell wall. The electrostatic interactions between bacteria and nanoparticles could also explain the higher efficiency of NPs with positive zeta potential. ${ }^{12,24}$ Both $S$. aureus and $E$. coli have negative global surface charges and most of the synthesized nanopowders compositions have a negative zeta potential. Consequently, the zeta potential alone could not explain the activity of the NPs studied. Nevertheless, a zeta potential effect cannot be totally excluded. It is interesting to note that the zeta potential of the NPs with more than 40 at\% of silver started to be less negative (Fig. 3) and this percentage corresponds to the beginning of activity against $E$. coli (Fig. 5). So, even if the zeta potential is negative above $40 \mathrm{Ag}$ at $\%$, it could lead to a lower repulsion force between nanoparticles and bacteria and thus to a better activity of Ag.

Finally, the impregnated $\mathrm{Cu}_{50}-\mathrm{Ag}_{50}$ NPs wound dressings exhibit bactericidal concentration dependent properties (Fig. 6). It is also interesting to note that this concentration effect is enhanced against $E$. coli. Indeed, for these bacteria, the inhibition zone increases by $50 \%$ when the impregnated NPs concentration doubles. For $S$. aureus, the effect is already clearly visible at very low concentrations and only a slight increase is observable ( $8 \%$ ) when the concentration doubles. One explication could be, once again, linked to the necessity to have a tight contact between the NPs and $E$. coli, for an ion diffusion important enough to see the effects on $S$. aureus. Nevertheless, our impregnated $\mathrm{Cu}_{50}-\mathrm{Ag}_{50}$ NPs wound dressings are effective against both $S$. aureus and $E$. coli even with a low concentration of NPs, which is of medical relevance. The core-shell insertion on the fibers of wound dressing is moreover relatively simple and the NPs present a large advantage compared to $\mathrm{Ag}^{+}$and/or $\mathrm{Cu}^{2+}$ solutions. The NPs behave indeed as a tank for silver and copper that only gradually released ions, which confers a persistence antibacterial efficacy. Furthermore, for the same material quantity, the nanometric scale exhibits much larger active surface compared to the micrometric one thus amplifying their properties. The core-shell structures allow using only a single type of particle and not a mix of copper and silver particles thus avoiding the heterogeneity of the repartition of these two elements in the wound dressing.

\section{Conclusions}

$\mathrm{Cu}-\mathrm{Ag}$ core-shell NPs were obtained using sonoelectrolysis followed by galvanic replacement reaction. The method chosen allows obtaining very fine NPs in aqueous media without using surfactants and by-products formation. Moreover, they are free of oxides traces. The $\mathrm{Cu}_{50}-\mathrm{Ag}_{50}$ synthesized particles are effective antimicrobial against both $S$. aureus and E. coli. Their use to 
functionalize wound dressing is of positive interest since they are already effective at low quantities. Toxicological tests on human cells are underway in order to verify the biocompatibility between $\mathrm{Cu}-\mathrm{Ag}$ core-shell NPs and human tissues.

\section{Acknowledgements}

This study was supported by the Conseil Régional de la Marne. We are also grateful to the URCA PICT IBiSA Imaging Center and to Chantal Grimplet for their technical support. The authors thank BSN Medical Company for the wound dressings gift. The authors thank T. Foster for the gift of S. aureus 8325-4 (prophage-free NCTC 8325) and Sylvie Ricord for the English corrections of this document.

\section{References}

1 K. Iwasaki, T. Itoh and T. Yamamura, Mater. Trans., 2005, 46, 1368.

2 J. M. Qiu, J. Bai and J. P. Wang, Appl. Phys. Lett., 2006, 89, 222506.

3 S. Cattarin and M. Musiani, Electrochim. Acta, 2007, 52, 2796.

4 K. W. Park, D. S. Han and Y. E. Sung, J. Power Sources, 2006, 163, 82.

5 C. Alexiou, R. Jurgons, C. Seliger and H. Iro, J. Nanosci. Nanotechnol., 2006, 6, 2762.

6 L. P. Balogh, S. S. Nigavekar, A. C. Cook, L. Minc and M. K. Khan, PharmaChem, 2003, 2, 94.

7 P. J. Debouttiere, S. Roux, F. Vocanson, C. Billotey, O. Beuf, A. Favre-Reguillon, Y. Lin, S. Pellet-Rostaing, R. Lamartine, P. Perriat and O. Tillement, Adv. Funct. Mater., 2006, 16, 2330.

8 H. Kawakami, K. Yoshida, Y. Nishida, Y. kikuchi and Y. Sato, ISIJ Int., 2008, 48, 1299.

9 H. Jing, Z. Yu and L. Li, J. Biomed. Mater. Res., Part A, 2008, 87, 33.

10 G. Grass, C. Rensing and M. Solioz, Appl. Environ. Microbiol., 2011, 77, 1541.

11 M. J. Hajipour, K. M. Fromm, A. A. Ashkarran, D. Jimenez de Aberasturi, I. Ruiz de Larramendi, T. Rojo, V. Serpooshan, W. J. Parak and M. Mahmoudi, Trends Biotechnol., 2012, 30, 499.

12 S. Sudheer Khan, A. Mukherjee and N. Chandrasekaran, Colloids Surf., B, 2011, 87, 129.

13 M. Guzman, J. Dille and S. Godet, Nanomedicine, 2012, 8, 45. 14 I. Sondi and B. Salopek-Sondi, J. Colloid Interface Sci., 2004, 275, 177.

15 J. S. Kim, E. Kuk, K. N. Yu, J. H. Kim, S. J. Park, H. J. Lee, S. H. Kim, Y. K. Park, Y. H. Park, C. Y. Hwang, Y. K. Kim, Y. S. Lee, D. H. Jeong and M. H. Cho, J. Nanomed. Nanotechnol., 2007, 3, 95.

16 K. H. Cho, J. E. Park, T. Osaka and S. G. Park, Electrochim. Acta, 2005, 51, 956.

17 Y. Zhang, Y. Chen, H. Zhang, B. Zhang and J. Liu, J. Inorg. Biochem., 2013, 118, 59.

18 P. Khare, A. Sharma and N. Verma, J. Colloid Interface Sci., 2014, 418, 216.
19 J. P. Ruparelia, A. K. Chatterjee, S. P. Duttagupta and S. Mukherji, Acta Biomater., 2008, 4, 707.

20 N. Mat Zain, A. G. F. Stapley and G. Shama, Carbohydr. Polym., 2014, 112, 195.

21 M. Valodkar, S. Modi, A. Pal and S. Thakore, Mater. Res. Bull., 2011, 46, 384.

22 L. A. Tamayo, P. A. Zapata, N. D. Vejar, M. I. Azócar, M. A. Gulppi, X. Zhou, G. E. Thompson, F. M. Rabagliati and M. A. Páez, Mater. Sci. Eng., C, 2014, 40, 24.

23 G. Ren, D. Hu, E. W. C. Cheng, M. A. Vargas-Reus, P. Reip and R. P. Allaker, Int. J. Antimicrob. Agents, 2009, 33, 587.

24 P. K. Stoimenov, R. L. Klinger, G. L. Marchin and K. J. Klabunde, Langmuir, 2002, 18, 6679.

25 G. Franci, A. Falanga, S. Galdeiro, L. Palomba, M. Rai, G. Morelli and M. Galdeiro, Molecules, 2015, 20, 8856.

26 A. Azam, A. S. Ahmed, M. Oves, M. S. Kahan and A. Memic, Int. J. Nanomed., 2012, 7, 3527.

27 H. J. Lee and S. H. Jeong, Text. Res. J., 2004, 74, 442.

28 L. Esteban-Tejeda, F. Malpartida, A. Esteban-Cubillo, C. Percharroman and J. S. Moya, Nanotechnology, 2009, 20, 085103.

29 S. Azlin-Hasim, M. C. Cruz-Romero, T. Ghoshal, M. A. Morris, E. Cummins and J. P. Kerry, Innovative Food Sci. Emerging Technol., 2015, 27, 136.

30 T. Maneerung, S. Tokura and R. Rujiravanit, Carbohydr. Polym., 2008, 72, 43.

31 R. Dastjerdi, M. Montazer and S. Shahsavan, Colloids Surf., A, 2009, 345, 202.

32 S. D. Gittard, D. Hojo, G. K. Hyde, G. Scarrel, R. J. Narayan and G. N. Parsons, J. Mater. Eng. Perform., 2010, 19, 368.

33 S. Ravindra, Y. M. Mohan, N. N. Reddy and K. M. Raju, Colloids Surf., A, 2010, 367, 31.

34 S. Singh, H. C. Joshi, A. Srivastava, A. Sharma and N. Verma, Colloids Surf., A, 2014, 443, 311.

35 K. T. Chen, D. Ray, Y. H. Peng and Y. C. Hsu, Curr. Appl. Phys., 2013, 13, 1496.

36 R. Winand, J. Reisse and J. L. Delplancke, belgian pat. No. 09400555, 1994.

37 J. L. Delplancke, V. Di Bella, J. Reisse and R. Winand, Mater. Res. Soc. Symp. Proc., 1995, 372, 205.

38 A. Durant, J. L. Delplancke, V. Libert and J. Reisse, Eur. J. Org. Chem., 1999, 11, 2845.

39 M. Guzman, J. L. Delplancke, G. J. Long, J. Delwiche, M. J. Hubin-Franskin and F. Grandjean, J. Appl. Phys., 2002, 92, 2634.

40 V. Mancier, J. L. Delplancke, J. Delwiche, M. J. HubinFranskin, C. Piquer, L. Rebbouh and F. Grandjean, J. Magn. Magn. Mater., 2004, 281, 27.

41 V. Mancier, A. L. Daltin and D. Leclercq, Ultrason. Sonochem., 2008, 15, 157.

42 V. Mancier, C. Rousse-Bertrand, J. Dille, J. Michel and P. Fricoteaux, Ultrason. Sonochem., 2010, 17, 690.

43 P. Fricoteaux and C. Simon, J. Phys. Chem. B, 2005, 109, 20449.

44 S. Levi, C. Rousse, V. Mancier, J. Michel and P. Fricoteaux, J. Mater. Res., 2015, 30, 3518. 
45 Y. H. Peng, C. H. Yang, K. T. Chen, S. R. Popuri, C. H. Lee and B. S. Tang, Appl. Surf. Sci., 2012, 263, 38.

46 M. L. Knetsch and L. H. Koole, Polymers, 2011, 3, 340.

47 E. T. Hwang, J. H. Lee, Y. J. Chae, Y. S. Kim, B. C. Kim, B. I. Sang and M. B. Gu, Small, 2008, 4, 746.
48 J. Zhao, D. Zhang and X. Zhang, Surf. Interface Anal., 2015, 47, 529.

49 D. M. Tench and J. T. White, J. Mater. Sci., 1992, 27, 526. 